\section{Totally out of the question}

\section{Stuart Sutherland}

No Way: The Nature of the Impossible. Edited by Philip J. Davis and David Park. W.H. Freeman: 1987. Pp.325. \$17.95, $£ 17.95$.

\section{RUDYARD Kipling wrote:}

I'm the Prophet of the Utterly Absurd, Of the Patently Impossible and Vain.

The banjo's boast could be the theme song of creative scientists, who frequently make what seems impossible one day possible the next. Once upon a time it seemed impossible that the Universe was not eternal, that the Earth went round the Sun, that there was a finite velocity beyond which nothing could travel and that there could be a geometry that did not make the assumption that parallel lines never meet. Had there been anyone around to survey the Big Bang, he would surely have thought it quite impossible that one of its distant products would be mankind.

Professors Davis and Park have gathered together contributed chapters on 18 different subjects, ranging from chemistry to music and from biology to law. Each chapter sets out some of the impossibilities within the discipline it covers. The contributors for the most part write aimiably and clearly. They often provide fascinating glimpses of their own subjects, though they rarely illuminate the nature of the impossible.

It might have been helpful if the editors had distinguished more carefully between different kinds of impossibility. Within science, what is thought to be impossible becomes possible if the theoretical framework is changed. Physics successfully absorbed the fact that matter can be converted into energy. But - a point hardly noticed in the book - there are different degrees of impossibility. Suppose, for example, foreseeing the future through clairvoyance were found to be possible. The business of bookmakers and of allied professions such as stockbroking would be severely damaged, but of more importance physics would find it impossible to absorb the finding for it runs counter to one of its most far-reaching assumptions. The finding could not just be explained by developing a broader theory in the way newtonian physics falls out as a special case of relativity theory; it would either require a complete rethinking of the whole of physics or - more likely would have to be quietly ignored.

Apart from the impossibility of breaking the existing rules of a science, there are technological impossibilities which depend either on theoretical limits or on the limitations of practical techniques. For theoretical reasons, based on heat loss, a petrol engine cannot convert more than about two thirds of the energy in the petrol into mechanical energy to propel a car, but for practical reasons the efficiency of existing engines is very much lower than this. Similarly the switching times of gates on a computer are limited by thermal fluctuations which create errors, but the present rate at which operations can be performed (about $10^{7}$ per second) is well below the theoretically possible maximum. Yet even at a practical level the impossible often becomes possible. Although these topics are not mentioned in the book, it is not so long ago since heart transplants and blood dialysis would have been scoffed at. Surgeons are already at work to provide an artificial womb so that men can give birth, but even if the obscenity of some medicine makes it possible for a man to bear a baby one can feel fairly certain that babies will never bear men.

The impossibility of falsifying propositions that are true by definition (for example " $2+2=4$ ", or "nothing can be red and blue all over") is less interesting, except that even here the framework may change - as in the case of parallel lines never meeting - and life goes on.

One of the most interesting chapters examines how the law deals with impossible stipulations under a contract. In 1705 someone, who was clearly no mathematician, undertook to supply two grains of rye each Monday and to double the amount supplied on each successive
Monday for a year. He tried to escape the contract on the grounds that it was impossible to fulfil, but the judges took a different view. One announced "where a man will for a valuable consideration undertake to do an impossible thing, though it cannot be performed, yet he shall answer damages". The other more tersely pronounced "the defendant ought to pay something for his folly". Although the issue of impossible contracts has not been fully resolved, the law tends nowadays to take the sensible view that if someone knowingly commits himself to performing the impossible, he should be responsible for his promise, but if he has no reason to believe it to be impossible he may be absolved.

There is a devastating chapter on education that rightly notes that it is not a science and that not a single finding or theory in psychology is of any use to the practising educator. The chapter on psychology concentrates too heavily on a well worn theme - the impossibility of being a good parent. It might have been more interesting to discuss wider issues, such as the impossibility of finding happiness from within or the impossibility of deliberately changing oneself. But no book can discuss all impossibilities, which range from "you can't get an ought from an is" to "you can't get a man with a gun". Although No Way is not impossible to put down, it is impossible to resist dipping into it.

Stuart Sutherland is Director of the Centre for Research in Perception and Cognition, University of Sussex, Brighton BN1 9QG, UK.

\section{Against ignorance}

\section{Patricia Smith Churchland}

Philosophy and the Brain. By J. Z. Young. Oxford University Press: 1987. Pp.233. £12.95, \$22.50.

Neuroscience has progressed to the point where it has begun to impinge seriously and systematically upon our understanding of human nature. Although nothing like a full-scale theory has emerged, there are many entry-points where we can begin to make neurobiological sense of psychological states and processes: what it is to see, be awake or dreaming, feel pleasure and pain, and so forth.

Many philosophers have started to take on board the implications of recent developments in neuroscience, but there remains a diehard core for whom neuroscientific discoveries are irrelevant. Favouring the a priori approach to questions about what we are and how we work, they use the label 'scientism' for the view that neuroscience can provide enlightenment, even as - perhaps especially as - it changes our intuitive conceptions of ourselves. By hitching the pejorative 'ism' to the end of an otherwise respectable word, they convey the suggestion that science is encroaching on the territory of the humanities, where, apparently, it has no legitimate business. To such people the very idea that behaviour might have a neurobiological explanation seems demeaning to human dignity and self-esteem.

In Philosophy and the Brain, J. Z. Young tries to convince the sceptics that if they allowed themselves to know what research has revealed in the neurosciences, they would recognize that the $a$ priori approach is blinkered and stifling. They would see, too, that neurobiological explanations of human character and behaviour enhance rather than detract from the dignity of man, because they give us insight and understanding based on fact. Perplexed and dismayed by the policy of ignorance, Young has tried to assemble a sort of neuroscience-withouttears. By keeping the book short and minimizing technical language, he has tried to make it easy for philosophers to see why they should care about how the brain works. 